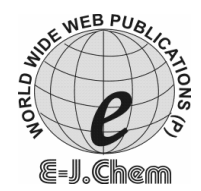

http://www.e-journals.net
ISSN: 0973-4945; CODEN ECJHAO

E-Journal of Chemistry

Vol. 5, No.3, pp. 511-514, July 2008

\title{
Spectrophotometric Estimation of Abacavir Sulphate in Pharmaceutical Formulations
}

\author{
N. APPALA RAJU, J. VENKATESWARA RAO*, \\ K. VANITHA PRAKASH and K. MUKKANTI ${ }^{\#}$ \\ Department of Pharmaceutical Chemistry, Sultan-Ul-Uloom College of Pharmacy, \\ Mount Pleasant, Road No. 3, Banjara Hills, Hyderabad-500 034. \\ "Institute of Science and Technology, Jawaharlal Nehru Technological University, \\ Kukatpally, Hyderabad -500072, India. \\ jvrao1963@yahoo.co.in
}

Received 19 November 2007; Accepted 10 January 2008

\begin{abstract}
Two simple, accurate, rapid and sensitive methods (A and B) have been developed for the estimation of abacavir sulphate in its pharmaceutical dosage form. The method A and B are based on the formation of chloroform extractable complex of abacavir sulphate with bromophenol blue (method A) and bromocresol green (method B), which shows absorbance maxima at 460 $\mathrm{nm}$ and $469 \mathrm{~nm}$ respectively. The absorbance-concentration plot is linear over the range of $1-10 \mathrm{mcg} / \mathrm{mL}$ for method $\mathrm{A}$ and $\mathrm{B}$ respectively. Results of analysis for all the methods were validated statistically and by recovery studies. The proposed methods are economical and sensitive for the estimation of abacavir sulphate in bulk drug and in its tablet dosage form.
\end{abstract}

Keywords: Ultraviolet-Visible Spectrophotometry, Abacavir sulphate, Bromophenol Blue (BPB), Bromocresol Green (BCG).

\section{Introduction}

Abacavir sulphate ${ }^{1}$ is chemically $\{(1 \mathrm{~S}, 4 \mathrm{R})-4-[2-$ Amino-6- (cyclopropylamino)-9H-purin-9$\mathrm{yl}$ ]-2-cyclopentene-1-methanol $\}$. It is a nucleoside reverse transcriptase inhibitor with antiretroviral activity against HIV. It is administered alone or in combination therapy with other antiretrovirals. Survey of literature reveals that the drug is determined by using High Performance Liquid Chromatography ${ }^{2-4}$ only. No spectrophotometric methods are reported. The present study describes simple, sensitive, accurate, rapid and economical spectrophotometric methods for the estimation of abacavir sulphate in bulk \& its tablet dosage forms. 


\section{Experimental}

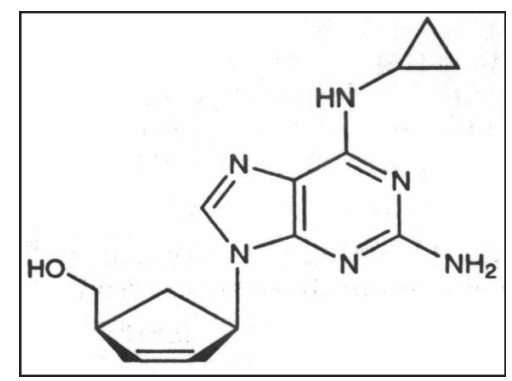

Structure of Abacavir

\section{Instrument}

Elico Ultraviolet-Visible double beam spectrophotometer SL-164 with $1 \mathrm{~cm}$ matched quartz cells was used for all spectral measurements.

\section{Reagents}

All the chemicals used were of analytical reagent grade. All the solutions were freshly prepared.

1. Acid phthalate buffer $\mathrm{pH} 3$

2. Bromophenol Blue $(0.1 \%)$

3. $\quad$ Acid phthalate buffer $\mathrm{pH} 2.4$

4. Bromocresol Green $(0.1 \%)$.

5. Chloroform AR grade.

\section{Procedure}

A standard stock solution containing $1 \mathrm{mg} / \mathrm{mL}$ was prepared by dissolving $100 \mathrm{mg}$ of abacavir sulphate in $100 \mathrm{~mL}$ of distilled water for method A and B. From this, a working standard solution containing $20 \mu \mathrm{g} / \mathrm{mL}$ was prepared for method A and B.

\section{Assay procedure}

\section{Method A}

Aliquots of standard drug solution of abacavir sulphate $0.5-5.0 \mathrm{~mL}(20 \mathrm{mcg} / \mathrm{mL})$ were taken and transferred into a series of $125 \mathrm{~mL}$ of separating funnels. To each funnel $2 \mathrm{~mL}$ of $0.1 \%$ BPB was added. Reaction mixture was shaken gently for $5 \mathrm{~min}$. Then $10 \mathrm{~mL}$ of chloroform was added to each of them. The contents were shaken thoroughly for $5 \mathrm{~min}$ and allowed to stand, so as to separate the aqueous and chloroform layer. Colored chloroform layer was separated out and absorbance was measured at $460 \mathrm{~nm}$ against reagent blank. Calibration curve was plotted from absorbance values so obtained

\section{Method B}

Aliquots of standard drug solution of abacavir sulphate $0.5-5.0 \mathrm{~mL}(20 \mathrm{mcg} / \mathrm{mL})$ were taken and transferred into a series of $125 \mathrm{~mL}$ of separating funnels. To each funnel $2 \mathrm{~mL}$ of $0.1 \%$ BCG was added. Reaction mixture was shaken gently for $5 \mathrm{~min}$. Then $10 \mathrm{~mL}$ of chloroform was added to each of them. The contents are shaken thoroughly for $5 \mathrm{~min}$ and allowed to stand, so as to separate the aqueous and chloroform layer. Colored chloroform layer was separated out and absorbance was measured at $469 \mathrm{~nm}$ against reagent blank. Calibration curve was prepared from absorbance values so obtained 


\section{Preparation of sample solution}

Twenty tablets of abacavir sulphate (Abamune, $300 \mathrm{mg}$, Cipla) were accurately weighed and powdered. Tablet powder equivalent to $100 \mathrm{mg}$ of abacavir sulphate was dissolved in $50 \mathrm{~mL}$ of distilled water, sonicated for 15 mins, filtered and washed with distilled water. The filtrate and washings were combined and the final volume was made to $100 \mathrm{~mL}$ with distilled water. The solution was suitably diluted and analyzed as given under the assay procedure for bulk samples. The results are represented in Table1. None of the excipients usually employed in the formulation of tablets interfered in the analysis of abacavir, by the proposed methods.

\section{Recovery Studies}

To ensure the accuracy and reproducibility of the results obtained, known amounts of pure drug was added to the previously analysed formulated samples and these samples were reanalyzed by the proposed method and also performed recovery experiments. The percentage recoveries thus obtained were given in Table 1.

Table 1. Assay and recovery of abacavir sulphate in tablet dosage form.

\begin{tabular}{cccccc}
\hline \multirow{2}{*}{$\begin{array}{c}\text { Tablet } \\
\text { formulation }\end{array}$} & Labeled Amount, mg & \multicolumn{2}{c}{$\begin{array}{c}\text { Amount Obtained by } \\
\text { proposed method, mg* }\end{array}$} & $\begin{array}{c}* * \% \text { Recovery by the } \\
\text { Proposed method }\end{array}$ \\
\cline { 3 - 6 } & & Method A. & Method B & Method A & Method B \\
\hline 1 & 300 & 297.9 & 301.5 & 99.3 & 100.5 \\
2 & 300 & 298.5 & 302.3 & 99.4 & 101.2 \\
3 & 300 & 301.3 & 297.3 & 100.4 & 99.1 \\
\hline
\end{tabular}

*Average of three determinations**After spiking the sample.

\section{Results and Discussion}

The optimum conditions were established by varying one parameter at a time and keeping the others fixed and observing the effect on absorbance of chromogen. In the present work method A and $\mathrm{B}$ have been developed for the estimation of abacavir sulphate from tablet formulation. The developed methods A and B are based on formation of chloroform extractable colored complexes with bromophenol blue and bromocresol green respectively. The conditions required for the formation of colored complexes were optimized. Statistical analysis was carried out and the results were found to be satisfactory. Relative standard deviation values were low that indicates the reproducibility of the proposed methods. Recovery studies were close to $100 \%$ that indicates the accuracy and precision of the proposed methods.

The optical characteristics such as absorption maxima, Beer's law limits, molar absorptivity and Sand ell's sensitivity are presented in Table 2.

Table 2. Optical characteristics and precision data

\begin{tabular}{lll}
\hline \multicolumn{1}{c}{ Parameters } & \multicolumn{1}{c}{ Method A } & \multicolumn{1}{c}{ Method B } \\
\hline$\lambda_{\max }, \mathrm{nm}$ & 460 & 469 \\
Beer's law limits, mcg/mL & $1-10$ & $1-10$ \\
Molar absorptivity, L/mol.cm & $1.174 \times 10^{3}$ & $8.877 \times 10^{3}$ \\
Sand ell's sensitivity, micrograms/cm ${ }^{2} / 0.001$ absorbance unit & 0.243 & 0.0322 \\
Regression Equation* (Y) Slope (m) Intercept (c) & $0.005-0.0046$ & $0.006-0.419$ \\
Correlation Coefficient(r) & 0.9999 & 0.9998 \\
Precision (\%Relative Standard Deviation) & 0.264 & 0.502 \\
Standard error of mean & 0.019 & 0.0037 \\
\hline
\end{tabular}

$* Y=m x+c$, where $X$ is the concentration in micrograms/ml and $Y$ is absorbance unit. 
The regression analysis using the method of least squares was made for slope (m), intercept (b) and correlation obtained from different concentrations and the results are summarized in Table 2.

\section{Conclusion}

The proposed methods are simple, sensitive, accurate and economical for the routine estimation of abacavir sulphate in bulk and in its tablet dosage form.

\section{Acknowledgement}

The authors are grateful to M/s Aurobindo Pharma, Hyderabad for the supply of abacavir sulphate as a gift sample and to the Principal, Sultan-Ul-Uloom College of Pharmacy, Hyderabad, for providing the necessary facilities to carry out the research work.

\section{References}

1. Martindale-The Complete Drug Reference, $34^{\text {th }}$ Ed., 2005 p 625.

2. Oezkan, Yalein, Savaser, Ayhan and Oezkan Sibel, J Liq Chrom Rel Technol. 2005, 28(3), 423.

3. Ravitch J R and Moseley C G, J.Chromatogr.B, 2001, 762(2), 165.

4. Predrag, Laban Aleksandra Markovic, Slavko and Milena, Anal Lett, 2004, 37(13), 2649.

5. Vanitha Prakash K, Venkateswar Rao J, Appala Raju $\mathrm{N}$ and Himabidu V, Int. J. Chem. Sci. 2007, 5(2), 603. 


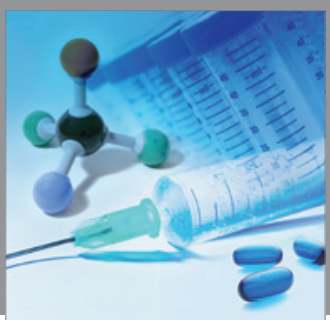

International Journal of

Medicinal Chemistry

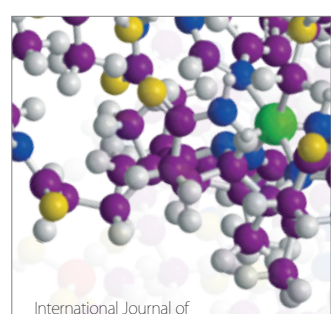

Carbohydrate Chemistry

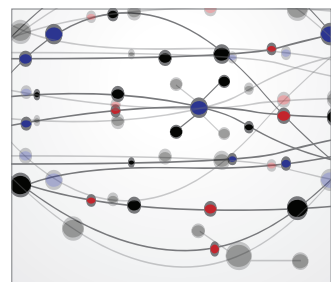

The Scientific World Journal
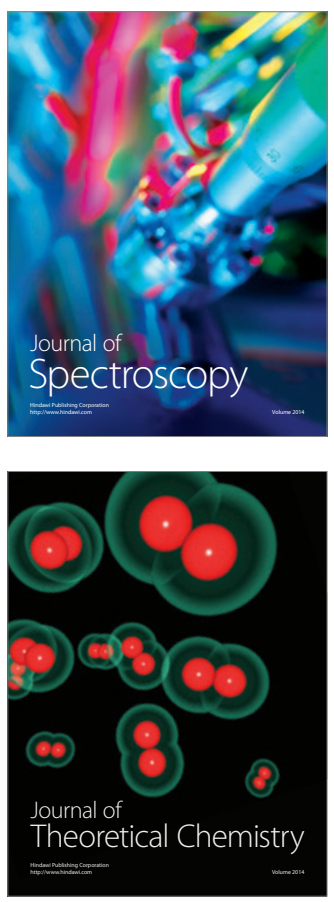
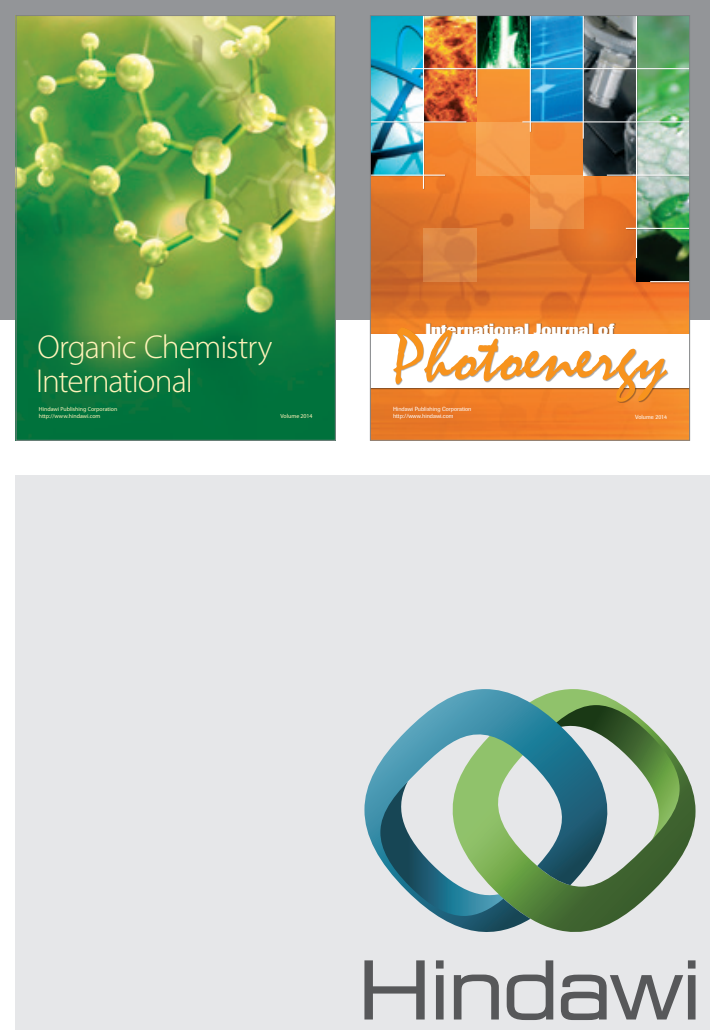

Submit your manuscripts at

http://www.hindawi.com
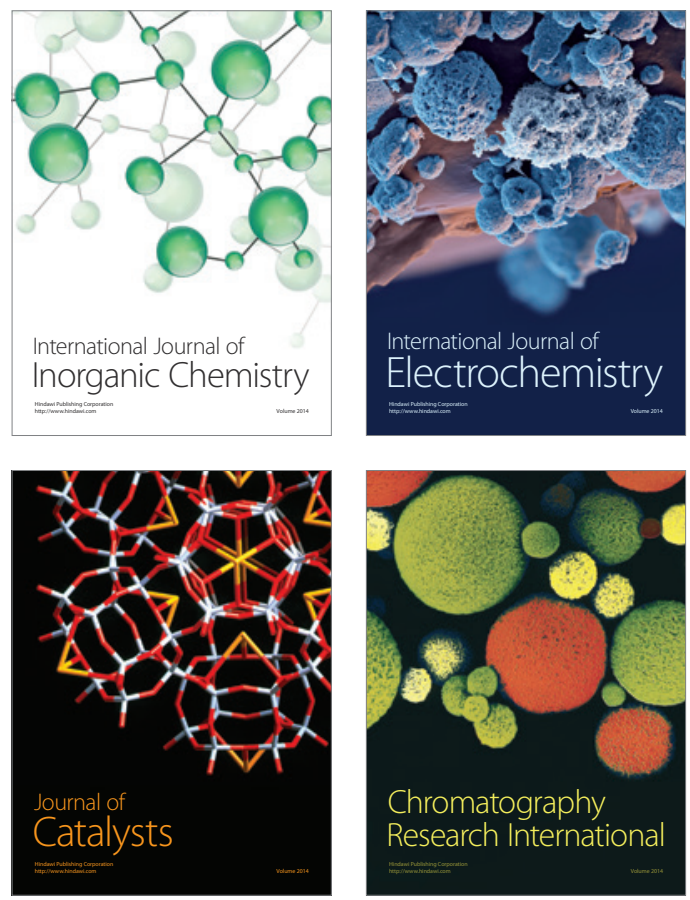
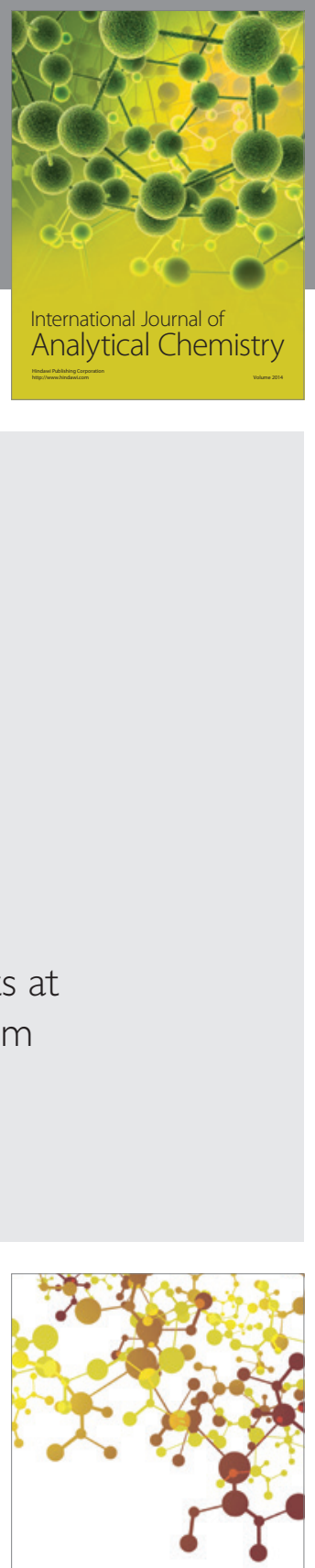

Journal of

Applied Chemistry
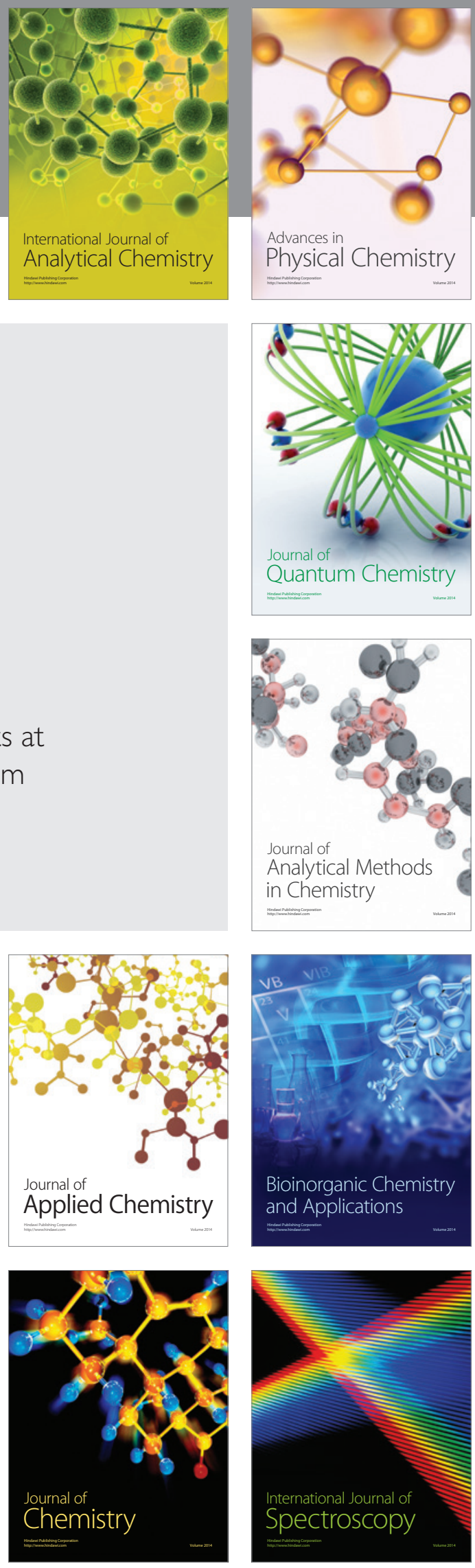